\title{
Causal Role of Motor Simulation in Turn-Taking Behavior
}

\author{
Lauren V. Hadley, ${ }^{1,2}$ Giacomo Novembre, ${ }^{2}$ Peter E. Keller, ${ }^{2}$ and Martin J. Pickering ${ }^{1}$ \\ ${ }^{1}$ School of Philosophy, Psychology, and Language Sciences, University of Edinburgh, Edinburgh EH8 9JZ, United Kingdom, and ${ }^{2}$ MARCS Institute for \\ Brain, Behaviour and Development, Western Sydney University, Penrith, New South Wales 2751, Australia
}

Overlap between sensory and motor representations has been documented for a range of human actions, from grasping (Rizzolatti et al., 1996b) to playing a musical instrument (Novembre and Keller, 2014). Such overlap suggests that individuals use motor simulation to predict the outcome of observed actions (Wolpert, 1997). Here we investigate motor simulation as a basis of human communication. Using a musical turn-taking task, we show that pianists call on motor representations of their partner's part to predict when to come in for their own turn. Pianists played alternating solos with a videoed partner, and double-pulse transcranial magnetic stimulation was applied around the turn-switch to temporarily disrupt processing in two cortical regions implicated previously in different forms of motor simulation: (1) the dorsal premotor cortex (dPMC), associated with automatic motor resonance during passive observation of hand actions, especially when the actions are familiar (Lahav et al., 2007); and (2) the supplementary motor area (SMA), involved in active motor imagery, especially when the actions are familiar (Baumann et al., 2007). Stimulation of the right dPMC decreased the temporal accuracy of pianists' (right-hand) entries relative to sham when the partner's (left-hand) part had been rehearsed previously. This effect did not occur for APMC stimulation without rehearsal or for SMA stimulation. These findings support the role of the dPMC in predicting the time course of observed actions via resonance-based motor simulation during turn-taking. Because turn-taking spans multiple modes of human interaction, we suggest that simulation is a foundational mechanism underlying the temporal dynamics of joint action.

Key words: joint action; motor simulation; music performance; premotor cortex; TMS; turn-taking

\section{Significance Statement}

Even during passive observation, seeing or hearing somebody execute an action from within our repertoire activates motor cortices of our brain. But what is the functional relevance of such "motor simulation"? By combining a musical duet task with a real-time repetitive transcranial magnetic stimulation protocol, we provide evidence indicating that the dorsal premotor cortex plays a causal role in accurate turn-taking coordination between a pianist and their observed interaction partner. Given that turn-taking behavior is a fundamental feature of human communication, we suggest that simulation is a foundational mechanism underlying the temporal dynamics of communicative joint action.

\section{Introduction}

Activation of motor brain areas while seeing or hearing an individual execute an action occurs for simple motor acts such as grasping and biting (Rizzolatti et al., 1996b; Buccino et al., 2001), as well as for more complex sequences such as speech (Scott et al., 2009), dance (Calvo-Merino et al., 2006), and music perfor-

\footnotetext{
Received May 8, 2015; revised Sept. 17, 2015; accepted Nov. 12, 2015.

Author contributions: L.V.H., G.N., P.E.K., and M.J.P. designed research; L.V.H. performed research; L.V.H. and G.N. analyzed data; L.V.H., G.N., P.E.K., and M.J.P. wrote the paper.

This work was supported by grants from the Experimental Psychology Society, the University of Edinburgh Development Trust, the MARCS Institute for Brain, Behaviour and Development, and an Australian Bicentennial Scholarship. L.V.H. is supported by the Economic and Social Research Council. We thank Alisdair Tullo for programming support and Patrick Sturt for performing as the duet partner.

The authors declare no competing financial interests.

Correspondence should be addressed to Lauren Victoria Hadley, School of Philosophy, Psychology, and Language Sciences, University of Edinburgh, 7 George Square, Edinburgh EH8 9JZ, UK. E-mail: lauren.hadley@cantab.net. DOI:10.1523/JNEUROSCI.1850-15.2015

Copyright $\odot 2015$ the authors $\quad 0270-6474 / 15 / 3516516-05 \$ 15.00 / 0$
}

mance (Novembre and Keller, 2014). Such research suggests that this activation is attributable to motor simulation of the observed actions (Kilner et al., 2007), whereby perceivers represent actions observed in others using their own motor repertoire (Wilson and Knoblich, 2005) and recruit at least some of the neural resources involved in actually performing those actions (Gallese and Goldman, 1998). This claim is supported by motor activation being stronger during observation of an action than a static actor and being similar to that elicited during action execution (Rizzolatti et al., 1996a; Grèzes and Decety, 2001; Rizzolatti and Fogassi, 2014).

A potential benefit of simulating observed actions is the facilitation of communicative interactions, in which predicting each other's upcoming output is essential for effective coordination (Pickering and Garrod, 2013). Music ensemble performance is particularly apt for testing this hypothesis, because success depends on musicians coordinating with high temporal precision (D'Ausilio et al., 2015). A recent piano duet study examined the 

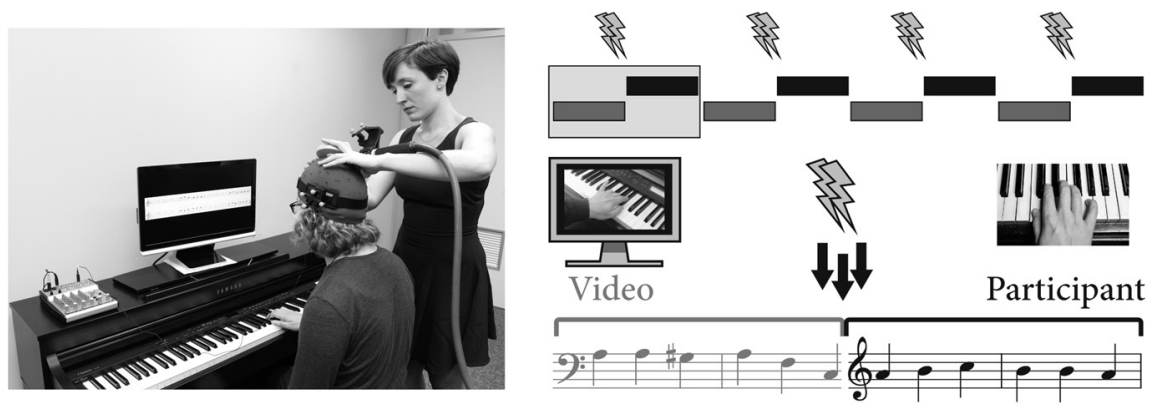

Figure 1. Example experimental setup and procedure. Position of the TMS coil was monitored by the experimenter in real time using a NeuroNavigator to stay within $5 \mathrm{~mm}$ of localization (NeuroNavigator not shown). The duets were structured as alternating two-bar turns as shown in the top schematic (with gray bars indicating the videoed pianist's part and black bars indicating the participant's part). The four applications of dTMS within each trial occurred at turn switch points. Below the schematic is an example of such a turn switch point, with arrows demonstrating the three alternative time points of stimulation ( 150 ms before, on, or 150 ms after the duet partner's final beat).

role of simulation in ensemble synchronization by applying double-pulse transcranial magnetic stimulation (dTMS) to a pianist's right primary motor cortex (M1) during a co-performer's tempo change (Novembre et al., 2014). Accuracy was disrupted only when the co-performer's (left-hand) part had been rehearsed beforehand, suggesting that simulation is involved in predicting actions within one's own motor repertoire. The current study extends the investigation of simulation to turn-taking behavior, which is more widespread than simultaneous production across human communicative interactions, including music (passing a melody between performers) and language (conversation).

Two forms of motor simulation are motor resonance and motor imagery (Jeannerod, 2001; Phillips-Silver and Keller, 2012). Motor resonance involves automatic (involuntary) activation of the motor system during passive observation of an action; motor imagery involves active (voluntary) imagination of oneself performing the observed action. The dorsal premotor cortex (dPMC), a region involved in action planning and control (Picard and Strick, 2001), is consistently active during passive observation of hand actions (Caspers et al., 2010). Furthermore, the $\mathrm{dPMC}$ is more strongly active when the observed action is within the observer's repertoire (Lahav et al., 2007), suggesting that motor resonance varies with strength of motor encoding. In contrast, the supplementary motor area (SMA), a region involved in movement initiation and beat perception (Grahn and Brett, 2007; Nachev et al., 2008), is not consistently active during passive observation (Filimon et al., 2007; Caspers et al., 2010; but see Macuga and Frey, 2012) but is consistently active during motor imagery (Kuhtz-Buschbeck et al., 2003; Lotze and Halsband, 2006). Similarly, the SMA is more strongly active when the observed action is within the observer's repertoire (Baumann et al., 2007), with motor imagery relying on experience performing an action (Lotze, 2013).

To investigate the role of simulation in interpersonal turntaking, we used dTMS to transiently disrupt processing in the $\mathrm{dPMC}$ and SMA in a musical task that involved passing a melody between a participant and a prerecorded co-performer (cf. Novembre et al., 2012, 2014). We manipulated whether or not participants had rehearsed and memorized their partner's part, because motor resonance and imagery are strongest for actions within one's repertoire (Baumann et al., 2007; Lahav et al., 2007). We hypothesized that, if motor resonance is used for temporally accurate turn-taking, stimulation of the APMC would impair entry accuracy when the partner's part had been rehearsed to a greater degree than when the partner's part had not been re- hearsed; if motor imagery is used for temporally accurate turn-taking, then stimulation of the SMA would impair entry accuracy when the partner's part had been rehearsed to a greater degree than when it had not been rehearsed.

\section{Materials and Methods}

Subjects. All 16 pianists (10 males) had at least 8 years of piano experience, practiced for at least $2 \mathrm{~h} /$ week, and gave informed written consent to participate. Participants' mean \pm SD age was $21.31 \pm 5.10$ years, and the mean $\pm \mathrm{SD}$ age at which they began piano tuition was $7.06 \pm$ 2.59. The experiment was conducted in accordance with TMS safety protocols (Rossi et al., 2009) following approval from the Human Research Ethics Committee at Western Sydney University.

Materials and task. Six 16-bar duets (with three beats per bar) were adapted from Bach chorales for the study. These were split into two-bar solo turns, which alternated between pianists. One pianist played sections of the left-hand bass line and the other played sections of the right-hand melody (Fig. 1), and both lines were reduced so that they were made up entirely of quarter-beat notes. Thus, the stimuli were not familiar to the participants. Eight skilled pianists who were not involved in the main experiment ( $\geq 10$ years of experience) marked the scores of these duets with fingerings that they considered appropriate, and the most frequently chosen fingerings were then printed on the scores.

Duets required pianists to use one hand each (one right, one left) and comprised a short series of alternating solos. Each solo turn was two bars long at 120 beats/min, spanning six beats at $500 \mathrm{~ms}$ each. Four duets were performed by the participant with their right hand, which implied simulation of their partner's left hand (Novembre et al., 2014). We investigated participants' simulation of their left hand for two reasons. First, this approach was consistent with previous studies reporting increasing motor excitability in response to rehearsed actions in piano players [D'Ausilio et al., 2006, in which motor evoked potential (MEPs) were elicited by stimulating the right motor cortex while pianists were listening to left-hand-rehearsed piano pieces]. Second, the disruptive effect of TMS on ipsilateral hand movement is less prominent for right, compared with left, motor cortex stimulation (Chen et al., 1997). To maintain participants' focus on both hands, we included two filler duets in which participants used their left hands. For all duets, the partner's part was recorded by a male pianist playing a digital piano (Yamaha Clavinova) in time with a metronome (mean absolute timing error, $62 \mathrm{~ms}$ ) and presented to participants in the experiment as a video.

Procedure. Participants were given the duets to rehearse and memorize (using specified fingerings) 1 week before the laboratory session. Two of the right-hand duets showed both left- and right-hand parts, and two showed only their own right-hand part (counterbalanced across participants). In the former, participants therefore rehearsed and memorized both their own and their partner's part ("familiar" condition), and, in the latter, they rehearsed and memorized their own part but never saw their partner's part ("unfamiliar" condition). In the laboratory, participants undertook a memorization check to ascertain that they could play their own and, in the familiar duets, their partner's part, accurately from memory. Participants were then introduced to the task through a series of practice trials without TMS.

Presentation software (Neurobehavioral Systems) controlled the timing of both the TMS and the audiovisual recordings. For the participant to hear both their own and their partner's output, the audio from Presentation was combined with that of the keyboard using a mixer (visible on the left of Fig. 1) and presented to the participant through headphones. The participant's keystroke timings were recorded in Presentation in tenths of milliseconds as serial signals via a specially designed 
A

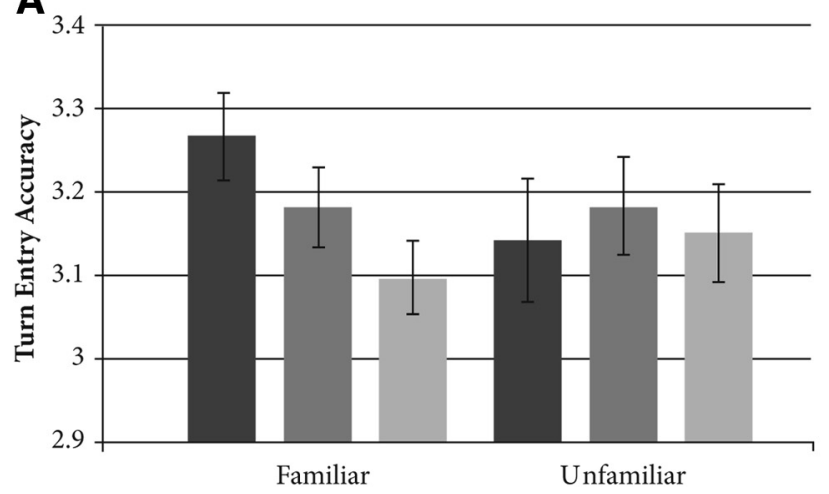

B

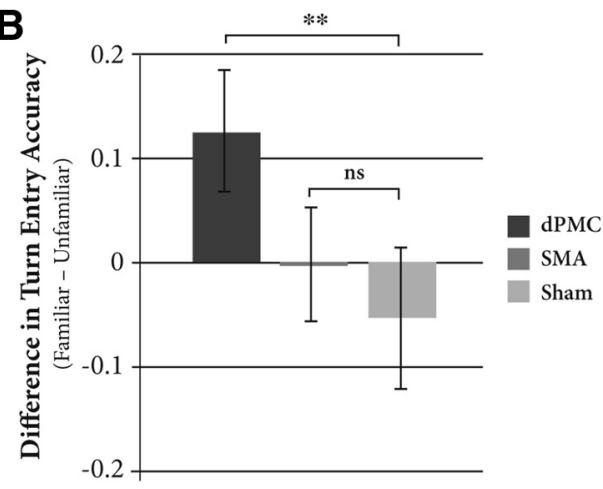

Figure 2. A, Mean turn entry accuracy by stimulation site (dPMC vs SMA vs sham) and familiarity (familiar vs unfamiliar). $\boldsymbol{B}$, Difference in turn-entry accuracy between the familiar and unfamiliar conditions by stimulation site (dPMC vs SMA vs sham). Error bars represent 1 SEM. ${ }^{* *} p<0.01 ; n s, p>0.1$.

device that converted the keyboard output from Musical Instrument Digital Interface format.

Participants performed 96 trials (duet performances) in total. They performed the four right-hand (experimental) duets 18 times each in an individually randomized order. Participants also performed the two lefthand (filler) duets nine times each, together with six catch trials (in which the video and audio recordings were mismatched) in an individually randomized order. Non-experimental trials were interspersed every four to six experimental trials. Before each trial, participants saw the notation of their part. These stimuli were presented on a 19-inch monitor, with viewing distance being $\sim 50 \mathrm{~cm}$. When ready, the participant pressed a button to initiate the duet performance. The participant was instructed to play the alternating turns with the videoed duet partner, matching his tempo $(120 \mathrm{bpm})$. To ensure that participants watched the video, the notation of the chorale was not present during the trial itself. Halfway through the experiment, participants had a break to practice the chorales once each, with notation including both hands when relevant (to strengthen the representation of the duet partner's part in the familiar condition).

dTMS (100 ms interpulse interval) was applied each time the participant entered to play after a solo by the videoed pianist, leading to four double pulses per experimental duet. The time point of the second stimulation pulse fell slightly before the videoed pianist's final beat $(-150$ $\mathrm{ms})$, on their final beat $(0 \mathrm{~ms})$, or slightly after their final beat $(+150 \mathrm{~ms})$ in a manipulation akin to jittering. The ideal position of the duet partner's final beat was based on the metronome that he heard during the recording stage. Entries of the participant were separated by $6 \mathrm{~s}$, and hence each double pulse was separated by at least $5.7 \mathrm{~s}$ (to avoid adaptation to TMS). Over the experiment, participants experienced 192 active double TMS pulses (plus 170 sham double pulses) in a total time of $2 \mathrm{~h}$ (including region localization and half-time break; Fig. 1).

Design. A within-subject design was used with two factors: (1) stimulation site (right dPMC, SMA, sham); and (2) familiarity (familiar: partner's part rehearsed previously; unfamiliar: partner's part not rehearsed previously). In addition, stimulation timing was jittered ( $150 \mathrm{~ms}$ before, on, or $150 \mathrm{~ms}$ after the partner's final beat) to allow for the possibility that the time course of simulation may be variable. Therefore, stimulation timing was randomized within the four participant entries in each trial, whereas stimulation site was kept constant within a given trial but randomized between trials. Participants completed 72 experimental trials, together with 18 filler and six catch trials.

TMS. A MagStim Rapid2 (Magstim) stimulator was used and applied with a $70 \mathrm{~mm}$ figure-of-eight coil. Individuals' resting motor thresholds were defined as the lowest intensity with which stimulation of the right M1 evoked at least 5 of 10 successive MEPs (with amplitude $>50 \mu \mathrm{V}$ ) in the left first dorsal interosseous muscle. While determining the resting motor threshold, muscular contraction (electromyography signal) in the target muscle was monitored visually, and full muscular relaxation was obtained. During the experiment, the paired pulses were applied online at $110 \%$ of this threshold (as used to cause temporary disruption in the studies by Rice et al., 2006; Cohen et al., 2009). The average \pm SD stimulation intensity during dTMS was $71 \pm 8.6 \%$ of maximum stimulator output.

The position of the TMS coil for both the APMC and SMA was ascertained from the left-hand representation of the right M1 (which was determined using an MEP-guided procedure; see above) in accord with previous research (Giovannelli et al., 2014). The position of the anterior border of the APMC was determined by moving the center of the junction of the TMS coil anterior from M1 by $3 \mathrm{~cm}$, keeping orientation constant (Picard and Strick, 2001; Siebner et al., 2003). The position of the SMA was determined by placing the center of the coil $2.5 \mathrm{~cm}$ anterior to the vertex (midpoint between the nasion and inion), handle pointing backward and coil wings parallel to the floor (Matsunaga et al., 2005; Hamada et al., 2009). In the sham condition, the coil was tiled $90^{\circ}$ away from the scalp over the right $\mathrm{M} 1$ hotspot, with the wing touching the scalp, the handle pointing $45^{\circ}$ posterior to the $x$-axis (Talairach coordinate system), and the magnetic field pulse directed ventrally toward the experimenter (standing on the right side of the participant; Fig. 1). Sham stimulation was conducted to control for any general effects of the auditory clicks associated with the stimulation process. Accurate positioning was maintained by the experimenter throughout the experiment (within $5 \mathrm{~mm}$ ) using the Polaris Spectra NeuroNavigator (Northern Digital).

Data analysis. Only turns in which the participant played their entire solo phrase correctly were analyzed (defined as all notes in the right order with no insertions). The accuracy of pianists' first keystroke was determined in relation to the unheard metronome underlying the duet partner's performance. The differences between these two timings (in milliseconds) were then converted into absolute values, which designate early entries and late entries as equally distant from the ideal response (Chen et al., 2008). Because absolute response time values have a lower bound of $0 \mathrm{~ms}$ and are hence not normally distributed, we log transformed our data as a standard correction for positive skew. One outlying pianist whose data were $>2.5$ SD from the mean turn timing error was removed, leaving 15 participants (mean $\pm \mathrm{SD}, 3.07 \pm 0.18$; outlier mean, 3.83 ). For those remaining, outlying entry timings were removed by participant (mean \pm 2.5 SDs, $2.91 \%$ entries removed).

\section{Results}

Pianists were generally very accurate at the task, showing a mean \pm SD turn-timing error of $32.7 \pm 28.5 \mathrm{~ms}$. As hypothesized, turn-timing accuracy varied depending on the stimulation site and familiarity of the partner's part $\left(F_{(2,28)}=4.484, p=\right.$ $0.020)$. This interaction was unaffected by stimulation timing $\left(F_{(4,56)}=0.236, p=0.917\right)$, although a main effect of timing showed that accuracy was highest when pulses occurred on (rather than before or after) the duet partner's final beat $\left(F_{(2,28)}=\right.$ 5.106, $p=0.013)$. Therefore, we collapsed the data across the three stimulation times and analyzed the familiar and unfamiliar conditions separately (Fig. 2A). 
In the unfamiliar condition, there was no effect of stimulation site $\left(F_{(2,28)}=0.296, p=0.746\right)$, but in the familiar condition, there was an effect of stimulation site $\left(F_{(1.394,19.520)}=6.114, p=\right.$ 0.015, Greenhouse-Geisser correction). We ran $t$ tests on the difference in performance between familiar and unfamiliar conditions at each stimulation site to investigate this effect (Fig. 2B). Although there was no difference in accuracy between stimulation of the SMA and $\operatorname{sham}\left(t_{(14)}=0.888, p=0.389\right)$, stimulation of the dPMC significantly impaired entry accuracy compared with sham $\left(t_{(14)}=3.197, p=0.006\right)$. This was attributable to stimulation of dPMC impairing accuracy compared with sham in the familiar condition $\left(t_{(14)}=2.717, p=0.017\right)$ but not in the unfamiliar condition $\left(t_{(14)}=-0.155, p=0.879\right)$.

\section{Discussion}

Following previous research showing activation of motor brain regions when individuals see or hear others executing actions, we investigated the role of perceptual-motor coupling in turn coordination. By using dTMS to disrupt neural processing in motor regions during musical turn-taking, we provide supporting evidence for simulation being causally involved in one's own entry accuracy. Our findings indicate that perceptual-motor coupling is not a simple byproduct of the repeated coexposure of particular actions with particular sounds or sights, but that it plays a functional role for prediction within interpersonal coordination (Novembre and Keller, 2014; Novembre et al., 2014). Furthermore, we investigated two forms of motor simulation through stimulation of two motor regions: (1) the $\mathrm{APMC}$, associated with motor resonance; and (2) the SMA, associated with motor imagery. We found that stimulation of the $\mathrm{APMC}$ around the turn switch point impaired pianists' entry timing when they were familiar with their duet partner's part, but not otherwise. We did not find evidence that disruption of the SMA led to inaccurate turn timing. These findings suggest that motor resonance is necessary for making temporal predictions in turn-taking, whereas motor imagery is not.

Importantly, our duets involved predefined gaps between turns and hence could have been completed using an internal beat-counting process (i.e., without simulation). However, our finding of entry accuracy disruption with dPMC stimulation in the familiar condition suggests that simulation is nonetheless relied on for temporal predictions when the observed action sequence has been encoded strongly through rehearsal. The lack of such an effect in the unfamiliar condition may be attributable to simulation being relied on to a lesser extent for actions outside of one's repertoire, disruption of weaker resonance being too subtle to detect, or motor regions being differentially active during observation of strongly and weakly encoded actions.

The coupling of an observed action and its motor representation has been reported in a number of domains outside of music performance, including language (Meister et al., 2007; Fischer and Zwaan, 2008; Scott et al., 2009). Because music and language have a number of similarities and require accurate temporal coordination between individuals for a successful interaction (Stivers et al., 2009; Ragert et al., 2013), we suggest that the use of simulation to predict a partner's actions may occur in both domains. The theory that simulation underlies prediction of a partner's utterance has strong empirical support (Pickering and Garrod, 2013). In the account of Pickering and Garrod, an addressee uses simulation to derive the speaker's production command, then runs this command through a forward model to predict the upcoming utterance and determine when to respond. In a similar way, we propose that a duettist awaiting their entry uses simulation and forward modeling to predict what their partner will play and, importantly, the appropriate time to enter. In the current experiment, rehearsal of the partner's part led to more accurate simulation and hence better prediction of the appropriate point of entry.

In summary, our results indicate that motor activation in the dPMC during partner observation is associated with the use of simulation to generate temporal predictions and that, when observed actions are represented within one's own motor system, this simulation is used in determining the timing of turn-taking. Because simulation has been proposed similarly to underlie timing of conversational turns in language, we suggest that the use of simulation to facilitate interpersonal coordination generalizes across domains. Turn-taking is the basis of human communication, spanning verbal (linguistic) and nonverbal (musical) interactions, and our findings indicate that simulation plays a role in regulating its temporal dynamics.

\section{References}

Baumann S, Koeneke S, Schmidt CF, Meyer M, Lutz K, Jancke L (2007) A network for audio-motor coordination in skilled pianists and nonmusicians. Brain Res 1161:65-78. CrossRef Medline

Buccino G, Binkofski F, Fink GR, Fadiga L, Fogassi L, Gallese V, Seitz RJ, Zilles K, Rizzolatti G, Freund HJ (2001) Action observation activates premotor and parietal areas in a somatotopic manner: an fMRI study. Eur J Neurosci 13:400-404. CrossRef Medline

Calvo-Merino B, Grèzes J, Glaser DE, Passingham RE, Haggard P (2006) Seeing or doing? Influence of visual and motor familiarity in action observation. Curr Biol 16:1905-1910. CrossRef Medline

Caspers S, Zilles K, Laird AR, Eickhoff SB (2010) ALE meta-analysis of action observation and imitation in the human brain. Neuroimage 50: 1148-1167. CrossRef Medline

Chen JL, Penhune VB, Zatorre RJ (2008) Moving on time: brain network for auditory-motor synchronization is modulated by rhythm complexity and musical training. J Cogn Neurosci 20:226-239. CrossRef Medline

Chen R, Gerloff C, Hallett M, Cohen LG (1997) Involvement of the ipsilateral motor cortex in finger movements of different complexities. Ann Neurol 41:247-254. CrossRef Medline

Cohen NR, Cross ES, Tunik E, Grafton ST, Culham JC (2009) Ventral and dorsal stream contributions to the online control of immediate and delayed grasping: a TMS approach. Neuropsychologia 47:1553-1562. CrossRef Medline

D’Ausilio A, Altenmüller E, Olivetti Belardinelli M, Lotze M (2006) Crossmodal plasticity of the motor cortex while listening to a rehearsed musical piece. Eur J Neurosci 24:955-958. CrossRef Medline

D’Ausilio A, Novembre G, Fadiga L, Keller PE (2015) What can music tell us about social interaction? Trends Cogn Sci 19:111-114. CrossRef Medline

Filimon F, Nelson JD, Hagler DJ, Sereno MI (2007) Human cortical representations for reaching: mirror neurons for execution, observation, and imagery. Neuroimage 37:1315-1328. CrossRef Medline

Fischer M, Zwaan R (2008) Embodied language: a review of the role of the motor system in language comprehension. Q J Exp Psychol (Hove) 61: 825-850. CrossRef Medline

Gallese V, Goldman A (1998) Mirror neurons and the simulation theory of mind-reading. Trends Cogn Sci 2:493-501. CrossRef Medline

Giovannelli F, Innocenti I, Rossi S, Borgheresi A, Ragazzoni A, Zaccara G, Viggiano MP, Cincotta M (2014) Role of the dorsal premotor cortex in rhythmic auditory-motor entrainment: a perturbational approach by rTMS. Cereb Cortex 24:1009-1016. CrossRef Medline

Grahn JA, Brett M (2007) Rhythm and beat perception in motor areas of the brain. J Cogn Neurosci 19:893-906. CrossRef Medline

Grèzes J, Decety J (2001) Functional anatomy of execution, mental simulation, observation, and verb generation of actions: a meta-analysis. Hum Brain Mapp 12:1-19. CrossRef Medline

Hamada M, Hanajima R, Terao Y, Okabe S, Nakatani-Enomoto S, Furubayashi T, Matsumoto H, Shirota Y, Ohminami S, Ugawa Y (2009) Primary motor cortical metaplasticity induced by priming over the supplementary motor area. J Physiol 587:4845-4862. CrossRef Medline

Jeannerod M (2001) Neural simulation of action: a unifying mechanism for motor cognition. Neuroimage 14:S103-S109. CrossRef Medline 
Kilner JM, Friston KJ, Frith CD (2007) Predictive coding: an account of the mirror neuron system. Cogn Process 8:159-166. CrossRef Medline

Kuhtz-Buschbeck JP, Mahnkopf C, Holzknecht C, Siebner H, Ulmer S, Jansen O (2003) Effector-independent representations of simple and complex imagined finger movements: a combined fMRI and TMS study. Eur J Neurosci 18:3375-3387. CrossRef Medline

Lahav A, Saltzman E, Schlaug G (2007) Action representation of sound: audiomotor recognition network while listening to newly acquired actions. J Neurosci 27:308-314. CrossRef Medline

Lotze M (2013) Kinesthetic imagery of musical performance. Front Hum Neurosci 7:280. CrossRef Medline

Lotze M, Halsband U (2006) Motor imagery. J Physiol Paris 99:386-395. CrossRef Medline

Macuga KL, Frey SH (2012) Neural representations involved in observed, imagined, and imitated actions are dissociable and hierarchically organized. Neuroimage 59:2798-2807. CrossRef Medline

Matsunaga K, Maruyama A, Fujiwara T, Nakanishi R, Tsuji S, Rothwell JC (2005) Increased corticospinal excitability after $5 \mathrm{~Hz}$ rTMS over the human supplementary motor area. J Physiol 562:295-306. CrossRef Medline

Meister IG, Wilson SM, Deblieck C, Wu AD, Iacoboni M (2007) The essential role of premotor cortex in speech perception. Curr Biol 17:1692-1696. CrossRef Medline

Nachev P, Kennard C, Husain M (2008) Functional role of the supplementary and pre-supplementary motor areas. Nat Rev Neurosci 9:856-869. CrossRef Medline

Novembre G, Keller PE (2014) A conceptual review on action-perception coupling in the musicians' brain: what is it good for? Front Hum Neurosci 8:603. CrossRef Medline

Novembre G, Ticini LF, Schütz-Bosbach S, Keller PE (2012) Distinguishing self and other in joint action. Evidence from a musical paradigm. Cereb Cortex 22:2894-2903. CrossRef Medline

Novembre G, Ticini LF, Schütz-Bosbach S, Keller PE (2014) Motor simulation and the coordination of self and other in real-time joint action. Soc Cogn Affect Neurosci 9:1062-1068. CrossRef Medline

Phillips-Silver J, Keller PE (2012) Searching for roots of entrainment and joint action in early musical interactions. Front Hum Neurosci 6:26. CrossRef Medline
Picard N, Strick PL (2001) Imaging the premotor areas. Curr Opin Neurobiol 11:663-672. CrossRef Medline

Pickering MJ, Garrod S (2013) An integrated theory of language production and comprehension. Behav Brain Sci 36:329-347. CrossRef Medline

Ragert M, Schroeder T, Keller PE (2013) Knowing too little or too much: the effects of familiarity with a co-performer's part on interpersonal coordination in musical ensembles. Front Psychol 4:368. CrossRef Medline

Rice NJ, Tunik E, Grafton ST (2006) The anterior intraparietal sulcus mediates grasp execution, independent of requirement to update: new insights from transcranial magnetic stimulation. J Neurosci 26:8176-8182. CrossRef Medline

Rizzolatti G, Fogassi L (2014) The mirror mechanism: recent findings and perspectives. Philos Trans R Soc Lond B Biol Sci 369:20130420. CrossRef Medline

Rizzolatti G, Fadiga L, Gallese V, Fogassi L (1996a) Premotor cortex and the recognition of motor actions. Brain Res Cogn Brain Res 3:131-141. CrossRef Medline

Rizzolatti G, Fadiga L, Matelli M, Bettinardi V, Paulesu E, Perani D, Fazio F (1996b) Localization of grasp representations in humans by PET. 1. Observation versus execution. Exp Brain Res 111:246-252. Medline

Rossi S, Hallett M, Rossini PM, Pascual-Leone A (2009) Safety, ethical considerations, and application guidelines for the use of transcranial magnetic stimulation in clinical practice and research. Clin Neurophysiol 120:2008-2039. CrossRef Medline

Scott SK, McGettigan C, Eisner F (2009) A little more conversation, a little less action-candidate roles for the motor cortex in speech perception. Nat Rev Neurosci 10:295-302. CrossRef Medline

Siebner HR, Filipovic SR, Rowe JB, Cordivari C, Gerschlager W, Rothwell JC, Frackowiak RS, Bhatia KP (2003) Patients with focal arm dystonia have increased sensitivity to slow-frequency repetitive TMS of the dorsal premotor cortex. Brain 126:2710-2725. CrossRef Medline

Stivers T, Enfield NJ, Brown P, Englert C, Hayashi M, Heinemann T, Hoymann G, Rossano F, de Ruiter JP, Yoon KE, Levinson SC (2009) Universals and cultural variation in turn-taking in conversation. Proc Natl Acad Sci USA 106:10587-10592. CrossRef Medline

Wilson M, Knoblich G (2005) The case for motor involvement in perceiving conspecifics. Psychol Bull 131:460-473. CrossRef Medline

Wolpert DM (1997) Computational approaches to motor control. Trends Cogn Sci 1:209-216. CrossRef Medline 